\title{
De la ciudad a la montaña o el proceso de salvación del hombre en Engaños de mujeres y desengaños de hombres (1698) de Miguel de Montreal desengaños de hombres (1698) de Miguel de Montreal
}

\section{Tapsir Ba}

Universidad Cheikh Anta Diop

SENEGAL

tapsirb@yahoo.es

[Hipogrifo, (issn: 2328-1308), 7.1, 2019, pp. 531-540]

Recibido: 14-01-2019 / Aceptado: 20-02-2019

DOI: http://dx.doi.org/10.13035/H.2019.07.01.41

Resumen. Engañado y burlado por las numerosas damas que ha encontrado en sus peregrinaciones, don Jaime, protagonista de Engaños de mujeres y desengaños de hombres (1698) de Miguel de Montreal, llega, al cabo de un largo viaje a través de las ciudades de España (Barcelona, Valencia, Zaragoza...), a desengañarse. El castigo que le infligen las damas, expertas en engaños y burlas, le abren los ojos. Ahora comprende las vanidades del amor y las falsedades y la deslealtad de las mujeres, y en lo sucesivo no confía más que en la Reina del Cielo, cuyo monasterio de Montserrate le acoge. Las ciudades, centros de las tropelías y burlas vividas por los hombres, se revelan como lugares infernales, a diferencia de la montaña (la de Montserrat), lugar de refugio y, por tanto, de salvación.

Palabras clave. Engaño; desengaño; ciudad/aldea; elevación espiritual; burlas; amor; recorrido iniciático . 
Abstract. After being deceived and misled by many women in his long journey of life through different Spanish cities (Barcelona, Valencia, Zaragoza etc.), Don Jaime - protagonist of Engaños de mujeres y desengaños de hombres (1698) by Miguel de Montreal- gets disillusioned from the vanities of the day to day life and finds solace in the company of «The Queen of Heaven» and thus he takes refuge in her monastery, which is situated at Monserrate Mountain.

Keywords. Deception; Disillusionment; Towns/Villages; Spiritual elevation; Tricks; Love; Initiatory route.

\section{INTRODUCCIÓN}

A través de la obra Engaños de mujeres y desengaños de los hombres ${ }^{1}$, novela didáctica por excelencia, su «desconocidísimo autor», Miguel de Montreal, pone en escena al personaje de don Jaime, quien, del nacimiento a la muerte, vive entre engaños, calaveradas y tropelías. Desde luego, cabe notar que el carácter fuertemente didáctico de la obra no remite solo a lecciones de moral o a reflexiones políticas (que son muy abundantes y entrecortan la acción novelesca), engloba también episodios y peripecias. Ocurre que el héroe está metido en un torbellino de aventuras y de desplazamientos por muchas ciudades. Sin embargo, cabe reconocer que recorre también un sin número de otros lugares (aldeas, pueblos, etc.) y sufre varias tribulaciones y desventuras tales como el naufragio o el encarcelamiento. Estas peregrinaciones se parecen mucho a un viaje iniciático que va de los centros urbanos, asimilados a centros de perdición, malas conductas y fechorías, a la montaña de Montserrate, o sea, al centro de la buena conducta, del arrepentimiento. Se dibuja así, una especie de mapa de perfeccionamiento, de corrección continua del héroe. Dicho de otra manera, en la novela está diseñado un proceso de elevación espiritual, de salvación, que empieza en las ciudades y finaliza en la montaña, y ello vía la rus, la aldea.

\section{DE LA CIUDAD}

Pero entendámonos bien. El uso del término ciudad en su forma singular no significa que el héroe solo recorra una ciudad en los cuatro discursos de que consta la novela. Este singular es un singular colectivo y designa varias ciudades, varios centros urbanos donde el novelista Miguel de Montreal sitúa las aventuras vividas por el héroe don Jaime y ciertos personajes que él ha conocido durante sus peregrinaciones.

1. El título completo de la novela es: Engaños de mujeres y desengaños de los hombres, divididos en cuatro discursos históricos, políticos y morales que consagra a la soberana y milagrosa Reina de los Cielos María Santísima, Señora Nuestra de Montserrate, Madre de pecadores. Su autor, don Miguel de Montreal, vecino de esta Corte, Madrid, Imprenta de Manuel Ruiz de Murga, 1698. Citaré modernizando las grafías sin relevancia fonética, indicando el número de páginas entre paréntesis después de cada cita. Sobre el autor y sus ideas expresadas en Engaños..., ver Colón, 1989. Para el contexto de la narrativa barroca ver Moliné, 1982, Laspéras, 1987 y Ripoll, 1991, entre otros posibles trabajos. 
Don Jaime visitará primero Barcelona. Confiado desde niño a su tía, doña Móni$\mathrm{ca}^{2}$, para que vaya a la escuela y tenga carrera, el joven sucumbe rápidamente a las intrigas amorosas de doña Magdalena, su vecina, cuyo celoso hermano, don Josef, pone trabas a la relación y la combate:

Supo don Josef [...] el amoroso divertimiento que su hermana tenía; y considerando que no convenía a su crédito, después de haberle dado una advertida reprehensión a doña Margarita, condenó la puerta que subía al mirador, de suerte que quedó imposibilitada por aquel medio la dulce correspondencia de los amantes (p. 10).

Frustrado por tales medidas, don Jaime moriría lentamente si doña Clara, amiga de doña Magdalena, no viniera a socorrerle, restableciendo a través de billetes y cartas la comprometida relación: «Cumplió doña Clara lo que había ofrecido a doña Magdalena, siendo medianera e instrumento, llevando billetes de una y otra parte» (p. 12). Pero esta mediación, desgraciadamente, trae aparejada una complicación extraordinaria en la medida en que doña Clara, la tercera, se aprovecha de ella para utilizar al protagonista para vengarse de don Fadrique, un caballero napolitano que la había burlado después de haberle prometido casarse con ella: «Le pareció a doña Clara que podía ejecutar el engaño, tomando por instrumento a don Jaime y a doña Magdalena» (p. 12) ${ }^{3}$.

El héroe, pues, se va a encontrar metido en una especie de engranaje galante en el cual, convertido en un instrumento de las dos amigas, quienes procuran vengarse una de otra después de las medidas de represalias y enclaustramiento tomadas por don Josef, el hermano de doña Magdalena: «Vístese de amigable paz, finge afectuosos halagos doña Magdalena a su amiga doña Clara, para en trueque darle pesares» (p. 27).

Nuestro protagonista queda engañado y herido durante el fusilamiento consecutivo a su actuación en la doble galantería en derredor a las damas de Barcelona: «Don Josef, lleno de ira, sacando una pistola, la disparó y aunque vio caído a don Jaime [...] le aseguró con otra boca de fuego, dejándolo por muerto» (p. 33). Pero no está muerto, y don Jaime vuelve a su aldea natal, Colvatón, no lejos de la ciudad condal, donde pasa el periodo de su convalecencia pescando y cazando: «Alegres pasaba don Jaime los primeros días en la retirada aldea [...] unos a la caza, y otros en orilla del río Llobregat engañando al incauto pececillo» (p. 36).

Durante un paseo por las afueras de la aldea, llega don Jaime muy cerca del convento de Montserrate. Allí da con el anacoreta Anastasio. Este le cuenta su vida y le explica los motivos por los cuales ha venido a parar ahí. Las aventuras, infelices, que el asceta ha vivido con doña Vicenta en la ciudad de Valencia se parecen mucho a las suyas. Por eso, él no ha tenido más remedio que optar por una vida de anacore-

2. «Llevaron a don Jaime a Barcelona y recibiole doña Mónica [...] como a su único sobrino» (p. 6).

3. Y añade el narrador: «Urdió doña Clara la tela del engaño que había fomentado para la venganza de don Fadrique, quien la había burlado [...] fingiendo ser doña Magdalena (p. 12). 
ta, vida de soledad y aislamiento: «Aquí estoy exento de los tumultos de las ciudades y confusiones de las cortes: en esta apacible soledad no envidio nada» (p. 43).

Además de Barcelona, primera ciudad donde el autor sitúa los primeros lances del héroe, Valencia es otra ciudad que aparece también como un centro de engaños y deslealtad, del cual son víctimas los hombres. Una vez que don Jaime ve su salud restaurada por completo, su madre desea darle una segunda oportunidad y, sobre todo, aliviar su aburrimiento en la aldea: «Como era travieso y de natural audaz, [don Jaime] no se hallaba bien en la soledad ni apetecía tanta quietud» (p. 53). Así que le manda a Zaragoza, a casa de don Bernardo, «que había sido gran amigo de su difunto padre» (p. 55). Este caballero aragonés quiere ayudarle y, a su vez, le envía a casa de su hermano, un canónico de Valencia4

Pero en Valencia las cosas no irán tan bien como lo dejaba entender el amigo de su padre, ya que, a los pocos días de su llegada, doña Catalina, la sobrina del canónigo, se enamora de él y le introduce de lleno en una aventura rocambolesca hecha de fuga y viaje furtivo:

Valiéndose del silencio de la noche, siendo pasada la mitad de su curso en que descuidado de lo que podía sobrevenir descansaba el canónigo [...], salieron los dos [don Jaime y doña Catalina] (p. 98).

Pero siendo doña Catalina mujer libre, de conducta inestable e irreflexiva, decide, poco tiempo después de emprender la fuga, separarse de su galán, galán al que ha empujado a traicionar a su anfitrión y bienhechor, el canónigo. Se casa, pues, con don Lucas, amigo de don Jaime, quien les había ofrecido un escondite. El cambio no puede ser más repentino:

Todas las finezas, ansias, desvelos, lágrimas y suspiros que doña Catalina con cariñosas demonstraciones manifestaba a su amante don Jaime, en un instante las vio trocadas en desvíos e ingratitudes, mudando la inclinación en don Lucas (pp. 104-105).

A pesar de la acumulación de desgracias ahí sufridas, el protagonista no está viviendo más que una tregua, porque en Valencia, también lugar de ingratitud y deslealtad, se encuentra con don Ignacio, que como él viaja a Zaragoza, «ciudad a quien baña y ciñe con raudales de plata el caudaloso Ebro» (p. 117). Don Ignacio es víctima de la traición de su esposa, quien se ha entretenido con un caballero napolitano: «Y habrá quince días me dieron noticia que con un caballero que pasaba a Nápoles [mi mujer] se había embarcado» (p. 118). Como vemos, don Ignacio le cuenta a don Jaime su vida, marcada por el amor, la traición y la deslealtad de su esposa. Zaragoza, pues, como Barcelona y Valencia anteriormente, aparece como un lugar de fechorías y perversiones a costa de los hombres.

4. «Seréis bien asistido en la casa de un hermano que tengo en la ciudad de Valencia», le dice (p. 58). 
Aparece en el relato otra dama, doña Fulgencia, encontrada no lejos de Zaragoza cuando huye con su novio don Gregorio, odiado por su familia. Ella contará también sus desventuras ya que sus padres le han elegido como novio un galán al que no quiere:

Disgustados mis padres [...] dispusieron con toda presteza el que me desposase con uno de mis pretendientes, el más rico y el que menos lugar tenía en mi pecho (p. 131).

El novio propuesto por los padres de doña Fulgencia es de Orihuela, centro urbano donde, como podemos apreciar, ocurren nuevas deslealtades y castigos de los hombres.

Otra ciudad, Málaga, adonde acude el héroe en busca de refugio en casa de su amigo don Isidro, será otro lugar escenario de desventuras cruentas. «La chanza [...], la burla» (p. 140) y las violencias ejercidas sobre este «galán cascabel, que alimentaba su amor con ideas platónicas remontando sus pensamientos en superiores deidades» (p. 140), patentizan el carácter corrupto y vicioso de la ciudad.

Son estos lances importunos los que empujan al héroe a cambiar nuevamente de rumbo. Llega a Cádiz, donde, tras un naufragio, vivirá una de las aventuras más complejas y sorprendentes. En efecto, en Cádiz don Jaime asistirá a la burla que el general don Gabriel, comandante de la flota, le hace a doña Margarita, la esposa de don Jacomo, futuro Gobernador en las Indias. El marido engañado se ha quedado en la estacada, no ha podido embarcar. Su esposa ha confesado la traición de la cual es víctima. Oigámosla dirigirse a través de esta epopeya al burlador:

Ingrato y falso caballero, ¿es posible que no te compadecen mis penas y el confesarme tuya, y tú más ingrato me ofendes, al paso que te quiero más [...] como si nunca me hubieras visto? (p. 196).

Estas mudanzas y deslealtades afean la ciudad, desde luego. Pero todavía pasan ahí cosas peores. Este centro urbano es el escenario donde se cuentan las más sórdidas historias de prostitución: «Con tanto exceso vivía, dado al vicio y a los carnales deleites» (p. 199), reconoce el propio don Jaime, y así, al cabo de poco tiempo, «experimentó debilidad en su robusta salud, postradas sus fuerzas» (p. 199).

Cádiz será también el escenario de las artimañas de doña Fausta, la esposa de don Bartolomé, su anfitrión, la cual quiere seducirlo: «Aprovechaos de estas finezas [...], seréis correspondido con más excepción que otra cualquier persona» (p. 204).

La ciudad de Cádiz, asimismo, es donde el protagonista encuentra, sin reconocerla, a la «moribunda doña Ángela» (p. 242), que ha sido burlada y abandonada por el caballero napolitano. Ahora está en los huesos, después de haber llevado una vida de ramera: «Resuelta y libre me salí vagando villas y ciudades entregándome liviana a diferentes dueños» (p. 229).

También en las afueras de Cádiz el héroe don Jaime se encuentra con el caballero don Miguel, engañado y traicionado por doña Habela. La historia galante que 
este ha vivido en Astorga, «situada a poco más de cuatro leguas de León» (p. 212), viene a añadirse a los múltiples lances amorosos de los que no salen victoriosos los hombres. Estos, traicionados y, muy a menudo, perseguidos por el destino, huyen, se exilian buscando una mejora de su existencia, una elevación espiritual. Sus diferentes recorridos por varios centros urbanos están marcados por vicios, heridas, deslealtades y traiciones.

Así pues, Barcelona, Valencia, Zaragoza, Málaga, Orihuela, Cádiz y Astorga aparecen como centros de grandes desgracias, que representamos sintetizadas en la tabla siguiente.

\begin{tabular}{|l|l|l|l|l|}
\hline \multicolumn{1}{|c|}{ Ciudad } & Tipo de fechoría & \multicolumn{1}{c|}{ Autor } & \multicolumn{1}{c|}{ Víctima } & \multicolumn{1}{c|}{ Modo(s) } \\
\hline Barcelona & Deslealtad & $\begin{array}{l}\text { Doña Magdalena } \\
\text { Doña Clara }\end{array}$ & Don Jaime (3 veces) & Mentira/Disfraz \\
\hline Valencia & Deslealtad & $\begin{array}{l}\text { Doña Catalina } \\
\text { Doña Ángela } \\
\text { Dona Vicenta }\end{array}$ & $\begin{array}{l}\text { Don Jaime } \\
\text { Don Ignacio } \\
\text { Don Anastasio }\end{array}$ & Traición \\
\hline Zaragoza & Deslealtad & Doña Fulgencia & El novio de Orihuela & Traición \\
\hline Orihuela & Deshonestidad & Doña Fulgencia & El novio de Orihuela & Fuga \\
\hline Málaga & Burla & Dama principal & Don Isidro & Violencia \\
\hline Cádiz & & Doña Margarita & Don Jacomo & Traición \\
Traición
\end{tabular}

De esta tabla se nota que las siete ciudades (Barcelona, Valencia, Zaragoza, Orihuela, Málaga, Cádiz y Astorga), focos de las doce desventuras, le sirven al autor para declarar que el centro urbano es un infierno del que el hombre que no puede salir exento a menos que pase obligatoriamente por una especie de purgatorio, la rus, la aldea y todos los lugares afines como el mar, la quinta o las afueras de Barcelona.

\section{POR LA ALDEA}

La aldea de Colvatón, adonde vino a parar el padre del protagonista después de arruinarse en la ciudad de Barcelona con su vida disoluta y engañadora, representa el punto de partida de los pasos para una purificación. Ese caballero que llevó en la corte una existencia de sibarita tuvo que replegarse a su pueblo por haber perdido todos los medios de subsistencia:

A corta distancia de este sagrado sitio [Montserrate] yace una aldea que se llama Colvatón, adonde se retiró un caballero, natural de la ciudad de Barcelona, con su esposa y familia, al amparo de una mediana hacienda de campo que tenían [...] obligado de la necesidad por haber con excesivos gastos despendido un gran caudal [...] queriendo mantener ostentaciones y desvanecimientos... (p. 2). 
Esta retirada le vino bien a don Dalmao, el caballero arruinado, porque en muy breve tiempo pudo salir del atolladero y encontrar, de nuevo, la felicidad:

Gustoso vivía don Dalmao [...] con lo poco que fructificaba la hacienda de campo, a que le fue preciso ceñirse y olvidar divertimientos y paseos, que le tenían embelesado y destruido en la ciudad; de suerte que, pasados cuatro meses, se hallaba muy contento, gozando de vida quieta (pp. 2-3).

La vuelta del contento y la quietud, o sea la vuelta a una existencia mejorada5, no ha podido efectuarse sin este tránsito rural que bien se parece a un purgatorio. De este purgatorio se beneficia don Dalmao ya que enseguida se nos anuncia el nacimiento del hijo, el protagonista de la novela.

Además, este recorrido de la ciudad al campo (y de la ruina y los engaños a una situación mejorada) es como una puesta en abismo de los primeros episodios vivenciales del héroe. Recordemos que don Jaime, al igual que su progenitor, sufrió muchas desventuras con doña Magdalena y su amiga doña Clara que le pusieron en peligro de muerte. Herido por los disparos de don Josef, el hermano ofendido de doña Magdalena, él vino a curarse y purgarse en la aldea familiar: «Alegres pasaba don Jaime los primeros días en la retirada aldea, divirtiendo molestas memorias de la ingrata doña Magdalena» (p. 36).

Igual que esta retirada, de la que se beneficia grandemente el protagonista, el descubrimiento de las afueras del «devoto sitio» de Montserrate constituye un eslabón esencial en la cadena de su purificación. Durante esta visita conoció, como ya indiqué anteriormente, al anacoreta don Anastasio, cuya vida galante con doña Vicenta tiene paralelismos con la suya. En efecto, cuanto dice don Anastasio de su dama puede decirlo también don Jaime de doña Magdalena. Sus existencias son, pues, muy similares, y se aprecia que Miguel de Montreal utiliza otra vez el procedimiento de la puesta en abismo para reforzar el parecido entre la situación de ambos varones. Sin olvidar que don Jaime aprenderá bien la lección del anacoreta (señala que está «haciendo vida solitaria en este desierto, donde [...] logra el alma el poderse purificar», p. 43), y la pondrá en práctica en el momento adecuado de su vida.

La quinta donde se encontró con doña Catalina, la sobrina de su bienhechor el canónigo, es otro paradero rural en la trayectoria salvadora del protagonista. Ocurre que a partir del momento en que se da cuenta de que la ingrata dama lo abandonó por el falso amigo don Lucas, el héroe se pone a reflexionar sobre la vida galante y a tomar conciencia de sus errores. Escuchemos su queja dolorida, dirigida a doña Catalina:

-Por ti dejé los estudios y solo me desvelé en aprender el arte de amarte y las leyes de quererte, dejando por ti lo que más importaba a mis conveniencias y lo que más quería. Y tú, desconocida, en un instante, me dejaste (p. 113).

La estancia en la quinta viene a reforzar así el proceso tendente a expurgar los malos comportamientos del galán, empujándole a abrir los ojos sobre la vida:

5. Piénsese en lo que pregona fray Antonio de Guevara en su libro Menosprecio de corte y alabanza de aldea (1539). 
El ciego amante [...] no ve nada, ni oye, ni escucha consejos: no discurre, ni previene los inconvenientes, mientras está ciego en las tinieblas del amor, hasta que llora arrepentido los daños... (p. 112).

Este tercer elemento de la purificación vía el tránsito por la rus anuncia otro de mayor magnitud, el naufragio. Recuérdese el naufragio multiforme de los héroes de la novela de aventuras del Barroco. Muy a menudo, o casi siempre, el protagonista antes de llegar al éxito final (conquista del poder, reconocimiento por la casa real, restablecimiento de la justicia, etc.) pasa por algún naufragio, del cual sale desconocido hasta que por su participación en unas fiestas nobles (torneos, justas, etc.) logra recuperar su identidad y su rango perdidos. Pues bien, lo mismo parece ocurrirle a don Jaime. Su tentativa de viajar a las Indias fracasará: debido a una tormenta terrible naufraga, y tocará tierra en la playa de Orán ${ }^{6}$, posesión española en aquel entonces. Entonces decide que ya no quiere ir a las Indias, reconociendo que la Fortuna que le es contraria, según él, le perseguirá por doquier, así en la tierra como en el mar: «Que el que no la tenía [la Fortuna] en la tierra, menos la tendría en el mar; que no quería Indias, si había de pasar mar, que en todas partes hay Indias» (p. 157).

Esta renuncia llena de sensatez corrobora que el héroe ya no es el galán ciego, el calavera, el instrumento de las mujeres. Ya ha madurado. Ya sabe a dónde ir para probar fortuna. Ya está purificado. No le queda más remedio, si quiere salvar el pellejo, que escalar la montaña. Así pues, se va a completar ahora el recorrido iniciado en las ciudades pasando por la rus y que viene a culminarse en la montaña.

\section{LA MONTAÑA}

La descripción del paisaje de las afueras de la montaña en las primeras páginas de la novela suena como una invitación al héroe a subirla:

En el nobilísimo cuanto antiguo Principado de Cataluña hay un sitio tan hermoso a la vista como informe en su proporción; pues, próvida la naturaleza, engendró unas montañas tan eminentes que con dificultad puede la vista comprender su altura, causando al mismo tiempo amable diversión su variedad (p. 1).

¿Será una invitación a escalarla? Sí, pensamos. Pero más que esta especie de invitación que el autor hace al protagonista, interesa destacar el carácter milagroso de este locus amoenus: «En este [...] sitio, tan rústico al que no advierte su hermosa variedad, [está] la Concha de la mejor Perla [...], el monasterio [de] la milagrosa y soberana Reina de los Cielos» (p. 1), o sea, la Virgen de Montserrate. Es este milagroso sitio el que ha operado una metamorfosis extraordinaria en el anacoreta don Anastasio: «Aquí paso más gustoso con esta vida que el príncipe en su Corte» (p. 43). Pues bien, la eficacia del milagro se sentirá igualmente en la vida de don Jaime, aunque no de forma inmediata. Hay que señalar que, después de esta visita al asceta don Anastasio, el protagonista de la novela no se rindió inmediatamente a

6. «Orán, donde mantiene nuestro católico monarca (que Dios guarde) su cristiano celo al culto divino» (p. 157) 
la soledad de este desierto. Siguió sus aventuras en Cádiz, que representa, de entre todos los centros urbanos visitados por el héroe, el más peligroso, el más "infernal".

En Cádiz, no lo olvidemos, el héroe asistió a la burla del general de la flota a la esposa del futuro gobernador. En Cádiz vino a aclararse (es la página 228 del relato, en su cuarto Discurso) la suerte de doña Ángela anunciada desde la página 81, en el segundo Discurso, o sea 147 páginas antes. La transformación de doña Ángela casi en un esqueleto, en una ramera despreciada, así como las enfermedades graves que sufre don Jaime y su encarcelamiento suponen el culmen de todos los males ocurridos en los diversos centros urbanos. Es entonces cuando nuestro héroe, «cansado con tantos desengaños, cayendo en la cuenta, con lo que había tocado visiblemente, a costa de tantos sobresaltos y peligros», no puede más que hacer un balance de su vida. Prestémosle atención:

[Hizo] reflexión en su memoria de la ingratitud que experimentó de doña Magdalena en Barcelona, la inconstancia de doña Catalina en Valencia y las crueles traiciones de doña Fausta en Cádiz, y en las demás, recopilando desengaños con sus facilidades, malicias, cautelas y deshonor con que algunas mujeres ciegan al que inadvertidamente se deja llevar de sus engaños halagüeños (p. 243).

¡El pleito es inapelable! La condena de esta vida lujuriosa es definitiva. El protagonista tiene que pasar página, y la nueva página no es otra que la de la «vida solitaria» (p. 245):

Y teniendo muy presente el vistoso monte y sitio de Montserrate, por donde había pasado y comunicado con aquel anacoreta, que estaba haciendo vida solitaria en aquel desierto [...], se partió a él (p. 244).

\section{CONCLUSIÓN}

Como conclusión podemos señalar que el héroe del relato de Miguel de Montreal, Engaños de mujeres y desengaños de hombres (1698), para poder llegar a la elevación moral final, tuvo que transitar por las aldeas para purificarse. Y que, en fin, la montaña constituye el puerto seguro de salvación, lejos de «las tormentas peligrosas del borrascoso mar del mundo» (p. 247).

\section{BiBLIOgRAFÍA}

Colón, Isabel, «Los Engaños de mujeres de Miguel de Montreal», Diálogos hispánicos de Ámsterdam, 8.1, 1989 (monográfico dedicado a El teatro español a fines del siglo XVII. Historia, Cultura y Teatro en la España de Carlos II), pp. 111-124.

Guevara, Antonio de, Menosprecio de corte y de alabanza de aldea, ed. Eduardo Creus Visiers, Madrid, Cátedra, 1984. 
Laspéras, Jean-Michel, La nouvelle en Espagne au Siècle d'Or, Montpellier, Montpellier Publication de la Recherche, 1987.

Moliné, Georges, Du roman grec au roman baroque: un art majeur du genre narratif en France sous Louis XIII, Toulouse, Université de Toulouse-Le Mirail, 1982.

Montreal, Miguel de, Engaños de mujeres y desengaños de hombres, Madrid, Imprenta de Manuel Ruiz de Murga, 1698.

Ripoll, Begoña, La novela barroca. Catálogo bio-bibliográfico (1620-1700), Salamanca, Ediciones Universidad de Salamanca, 1991. 